\title{
Efeito da aplicação de glazeamento utilização solução de óleo de soja e água sobre os parâmetros físicos de qualidade do pão
}

\author{
R. A. ZAMBELLI ${ }^{1}$, L. F. L. HERCULANO ${ }^{1}$, G. K. PINHEIRO ${ }^{1}$, L. I. F. PINTO ${ }^{1}$, D. L. \\ BRASIL ${ }^{1}$, E. C. SANTOS-JUNIOR ${ }^{1}$, E. R. PONTES ${ }^{1}$ e D. F. PONTES ${ }^{1}$. \\ ${ }^{1}$ Universidade Federal do Ceará, Departamento de Tecnologia de Alimentos. \\ E-mail para contato: Zambelli@alu.ufc.br
}

\begin{abstract}
RESUMO - O estudo teve como objetivo estudar a ação do óleo de soja como agente de glazeamento nos parâmetros físicos de pães. No experimento foi utilizado o delineamento composto central rotacional, onde o óleo de soja e a água foram as variáveis independentes do estudo, que foram estudadas nos níveis de $0 \mathrm{~mL}$ a $50 \mathrm{~mL}$ de incorporação. Seu efeito sobre o fator de expansão, volume específico e produzido, densidade e índice de expansão foram avaliados pela metodologia de superfície de resposta. A região otimizada do volume específico foi para valores superiores a 3,60 $\mathrm{mL} / \mathrm{g}$, com solução composta a partir de $30 \mathrm{~mL}$ de água e até $5 \mathrm{~mL}$ de óleo de soja, resultado semelhante apresentou o volume produzido com valores acima de $30 \mathrm{~mL}$. A densidade foi afetada negativamente pelo óleo de soja, promovendo o seu aumento, o que não é desejado. Para o índice de expansão, a região ótima foi atingida quando não houve adição do óleo na solução e até $15 \mathrm{~mL}$ produziu fatores de expansão acima de $2,00 \mathrm{~cm}^{3}$.
\end{abstract}

\section{INTRODUÇÃO}

O hábito do consumidor é sempre consumir pães frescos, no entanto, após o processo de forneamento o pão já começa a sofrer reações de deterioração como a retogradação do amido e o seu respectivo endurecimento, prejudicando a sua qualidade sensorial. Atualmente, existem várias técnicas que tem por objetivo melhorar a palatabilidade do pão durante a sua estocagem, como por exemplo, com o uso de aditivos, emulsificantes, hidrocolóides e enzimas, bem como pela otimização de condições de forneamento e a utilização de soluções de glazeamento (Bárcenas e Rosell, 2006; Caballero et al., 2007; Ribotta et al., 2008).

Flander et al. (2007) afirmam que existem vários métodos para prolongar a vida útil de pães, entre eles, a nova técnica de glazeamento ou vitrificação aparenta ser um dos processos eficazes para a melhoria da qualidade do pão. Jahromi et al., (2012) verificaram melhoria na qualidade dos produtos após a utilização de soluções de glazeamento.

Existem diversos estudos sobre a utilização das mais diversas soluções de glazeamento e a sua relação com a umidade, propriedades de textura e estocagem, entretanto, não existem trabalhos que relacionem o uso destas soluções com os parâmetros físicos de qualidade utilizando a metodologia de superfície de resposta, diante disto, o trabalho tem como objetivo estudar o uso de solução contendo óleo de soja e água como agente de glazeamento em formulações de pães tipo forma visando à otimização dos parâmetros físicos de volume específico e produzido, fator de expansão, densidade e índice de expansão dos produtos. 


\subsection{METODOLOGIA}

\subsection{Delineamento Experimental}

O desenvolvimento das formulações de pães tipo forma foi realizado a partir de uma formulação padrão, cuja composição é: $100 \%$ de farinha de trigo; $55-60 \%$ de água, $10 \%$ de Gordura Vegetal Hidrogenada; 5\% de açúcar, 3,3\% de fermento biológico e 2\% de sal.

$\mathrm{Na}$ tabela 1 são apresentados as faixas de valores codificados e reais utilizados para os ensaios e na tabela 2 é apresentada a matriz do planejamento.

Tabela 1 - Variáveis e níveis do planejamento experimental completo $2^{2}$

\begin{tabular}{cccccc}
\hline & \multicolumn{4}{c}{ Níveis codificados e reais das variáveis independentes } \\
\cline { 2 - 6 } Variáveis Independentes & $\mathbf{- \alpha}=\mathbf{- 1 , 4 1}$ & $\mathbf{- 1}$ & $\mathbf{0}$ & $\mathbf{+ 1}$ & $\mathbf{+ \alpha}=\mathbf{+ 1 , 4 1}$ \\
Óleo de Soja $(\mathbf{m L})$ & 0 & 12,5 & 25 & 37,5 & 50 \\
Água $(\mathbf{m L})$ & 0 & 12,5 & 25 & 37,5 & 50 \\
\hline
\end{tabular}

*Em relação a farinha de trigo (base 100).

Para o desenvolvimento das formulações de pães tipo forma incorporadas com diferentes quantidades de óleo de soja e água foi utilizado o Delineamento Composto Central Rotacional (DCCR). Foi aplicado um planejamento fatorial $2^{2}$ completo, totalizando 11 ensaios.

Tabela 2 - Matriz do delineamento experimental com valores codificados e reais

\begin{tabular}{ccccc}
\hline Ensaios & Óleo de Soja & Água & Óleo de Soja $(\mathbf{m L})$ & Água $(\mathbf{m L})$ \\
\hline $\mathbf{1}$ & -1 & -1 & 12,5 & 12,5 \\
$\mathbf{2}$ & +1 & -1 & 37,5 & 12,5 \\
$\mathbf{3}$ & -1 & +1 & 12,5 & 37,5 \\
$\mathbf{4}$ & +1 & +1 & 37,5 & 37,5 \\
$\mathbf{5}$ & $-1,41$ & 0 & 0 & 25 \\
$\mathbf{6}$ & $+1,41$ & 0 & 50 & 25 \\
$\mathbf{7}$ & 0 & $-1,41$ & 25 & 0 \\
$\mathbf{8}$ & 0 & $+1,41$ & 25 & 50 \\
$\mathbf{9}$ & 0 & 0 & 25 & 25 \\
$\mathbf{1 0}$ & 0 & 0 & 25 & 25 \\
$\mathbf{1 1}$ & 0 & 0 & 25 & 25 \\
\hline
\end{tabular}

\subsection{Processamento dos Pães Tipo Forma}

Os ingredientes foram pesados em balança semi-analítica separadamente. Aplicou-se o método direto, onde todos os ingredientes são colocados simlutaneamente no início da etapa de mistura, com exceção do sal e água. Eles foram misturados em misturadora de escala semiindustrial durante 1 minuto em baixa velocidade para a homogeneização dos ingredientes, em seguida foi adicionada a água e misturada por 3 minutos em velocidade média, por último foi adicionado o sal e a massa foi misturada em alta velocidade por 6 minutos até o seu completo desenvolvimento. As massas foram divididas em porções de $250 \mathrm{~g}$ e moldadas na forma de 
elipses manualmente. Foram imersas nas soluções de óleo de soja/água correspondentes por 2 minutos, o excesso de solução remanescente na superfície das massas foi retirado por gravidade. Elas foram colocadas em fôrmas de folha galvanizada de ferro de chapa única para pão de forma sem tampa. Em seguida, colocadas em câmara de fermentação regulada a temperatura de $28{ }^{\circ} \mathrm{C} \pm 2{ }^{\circ} \mathrm{C}$ e $80 \%$ de umidade relativa, durante uma hora e trinta minutos. Ao final da fermentação, as massas foram assadas sem vapor durante 20 minutos a temperatura de $220{ }^{\circ} \mathrm{C}$ em forno elétrico de lastro Continental Advance Turbo®. Os pães foram resfriados durante uma hora em temperatura ambiente.

\subsection{Avaliação Física das Massas e dos Pães Tipo Forma}

Avaliação do processo de fermentação pela técnica de perfil livre de expansão: A expansão das massas durante o processo de fermentação foi avaliada através do procedimento experimental de Perfil Livre de Expansão desenvolvido por Gabric et al. (2011), com modificações, onde as massas foram consideradas como elipses truncadas, conforme ilustra a figura 1, foram medidas, a cada 10 minutos, as dimensões com o auxílio de régua milimetrada simples. As massas foram colocadas em fôrmas de alumínio com dimensões de $30 \mathrm{~cm}$ x 30 $\mathrm{cm}$ para permitir a sua livre expansão sem restrições dimensionais.

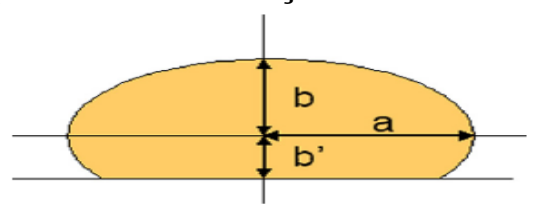

Figura 1 -Parâmetros de elipse truncada

O volume das massas para cada tempo de medição foi calculado com base na fórmula da elipse e sua rotação em torno do eixo y, conforme demonstra a equação 2.

$V\left(c m^{3}\right)=\pi a^{2}\left(\frac{2 b}{3}+b^{\prime}-\frac{b^{3}}{3 b^{2}}\right)$

Onde: $\mathrm{a}=$ largura da elipse $(\mathrm{cm}) ; \mathrm{b}=$ altura da elipse - do centro a elipse superior $(\mathrm{cm})$; $\mathrm{b}^{\prime}=$ altura da elipse - do centro para a parte inferior $(\mathrm{cm})$.

O fator de expansão do volume $\left(\mathrm{cm}^{3}\right)$ - VEF, foi calculado através da equação 3 .

$V E F=\frac{V-V_{o}}{V_{o}}$

Onde: $\mathrm{V}=$ Volume da massa ao longo do tempo de fermentação $\left(\mathrm{cm}^{3}\right) ; \mathrm{V}_{\mathrm{o}}=$ Volume incial da massa $\left(\mathrm{cm}^{3}\right)$.

Volume Produzido: Porções de massa de $15 \mathrm{~g}$, foram colocadas em provetas de $100 \mathrm{~mL}$ previamente esterilizadas para medição dos volumes das massas durante o processo de fermentação. Para o cálculo do volume produzido $(\Delta \mathrm{V})$ utilizou-se a subtração entre o volume final produzido, após uma hora e trinta minutos de fermentação e o volume inicial das massas na provetas, os resultados expressos em $\mathrm{mL}$.

Volume Específico: As massas dos pães foram determinadas em balança semi-analítica e expressa em gramas. $\mathrm{O}$ volume deslocado dos pães foi medido através de preenchimento de 
recipiente plástico e transparente com semente de painço expressando o resultado $\mathrm{mL}$. $\mathrm{O}$ volume específico foi calculado pela divisão do volume deslocado do pão (mL) pela sua massa (g), segundo método ${ }^{\circ} 72-10$ da AACC (1995).

Densidade: A densidade foi calculada através da relação inversa entre o volume deslocado e o peso da amostra assada.

Índice de Expansão: Para o cálculo do índice de expansão foi adaptada a medotologia utilizada por Silva et al. (2003) para pães de queijo. As massas foram moldadas na forma esférica para permitir as medições do diâmetro e da altura. com auxílio de régua milimetrada simples. O Índice de Expansão (IE) dos pães foi calculado através da equação 4:

Índice de Expansão $(I E)=\frac{\frac{\left(D_{p}+H_{p}\right)}{2}}{\frac{\left(D_{m}+H_{m}\right)}{2}}$

Onde: $\mathrm{D}_{\mathrm{p}}$ e $\mathrm{H}_{\mathrm{p}}=$ Diâmetro e altura dos pães após o forneamento (cm); $\mathrm{D}_{\mathrm{m}}$ e $\mathrm{H}_{\mathrm{m}}=$ Diâmetro e altura das massas moldadas $(\mathrm{cm})$.

\subsection{Análise Estatística}

A avaliação dos resultados dos parâmetros físicos no desenvolvimento das formulações através do delineamento composto central rotacional foi realizada por superfície de resposta e suas respectivas curvas de contorno após a análise de variância (ANOVA) e regressão, foi realizado teste de médias ao nível de 5\% de significância. A análise foi realizada no programa STATISTICA 7.0.

\section{RESULTADOS E DISCUSSÃO}

A tabela 3 apresenta os valores obtidos para os parâmetros físicos dos pães tipo forma.

Tabela 3 - Parâmetros físicos dos pães tipo forma

\begin{tabular}{cccccccc}
\hline Ensaios $^{1}$ & $\begin{array}{c}\text { Óleo } \\
(\mathbf{m L})\end{array}$ & $\begin{array}{c}\text { Água } \\
(\mathbf{m L})\end{array}$ & $\begin{array}{c}\text { Volume } \\
\text { Específico } \\
(\mathbf{m L} / \mathbf{g})\end{array}$ & $\begin{array}{c}\text { Densidade } \\
(\mathbf{g} / \mathbf{m L})\end{array}$ & $\begin{array}{c}\text { Índice de } \\
\text { Expansão }\end{array}$ & $\begin{array}{c}\text { Volume } \\
\text { Produzido } \\
(\mathbf{m L})\end{array}$ & $\begin{array}{c}\text { Fator de } \\
\text { expansão } \\
\left(\mathbf{c m}^{\mathbf{3}}\right)\end{array}$ \\
\hline E01 & 12,5 & 12,5 & $2,64^{\mathrm{c}} \pm 0,02$ & $0,38^{\mathrm{b}} \pm 0,01$ & $1,13^{\mathrm{e}} \pm 0,01$ & $22,00^{\mathrm{c}} \pm 1,00$ & $1,48^{\mathrm{d}} \pm 0,03$ \\
E02 & 37,5 & 12,5 & $2,49^{\mathrm{d}^{\mathrm{d}} \pm 0,05}$ & $0,41^{\mathrm{a}} \pm 0,01$ & $1,11^{\mathrm{e}} \pm 0,01$ & $17,66^{\mathrm{e}} \pm 1,15$ & $1,37^{\mathrm{e}} \pm 0,01$ \\
E03 & 12,5 & 37,5 & $2,93^{\mathrm{b}} \pm 0,01$ & $0,36^{\mathrm{b}} \pm 0,01$ & $1,26^{\mathrm{c}} \pm 0,01$ & $22,67^{\mathrm{c}} \pm 1,52$ & $1,78^{\mathrm{b}} \pm 0,01$ \\
E04 & 37,5 & 37,5 & $2,42^{\mathrm{d}^{\mathrm{d}} \pm 0,01}$ & $0,43^{\mathrm{a}} \pm 0,01$ & $1,05^{\mathrm{f}} \pm 0,02$ & $13,00^{\mathrm{f}} \pm 1,00$ & $1,39^{\mathrm{d}} \pm 0,01$ \\
E05 & 0 & 25 & $3,19^{\mathrm{a}} \pm 0,02$ & $0,28^{\mathrm{e}} \pm 0,01$ & $1,38^{\mathrm{a}} \pm 0,01$ & $30,33^{\mathrm{a}} \pm 2,08$ & $2,05^{\mathrm{a}} \pm 0,04$ \\
E06 & 50 & 25 & $2,58^{\mathrm{c}} \pm 0,07$ & $0,37^{\mathrm{b}} \pm 0,01$ & $1,19^{\mathrm{d}} \pm 0,01$ & $19,66^{\mathrm{d}} \pm 0,57$ & $1,55^{\mathrm{de}} \pm 0,03$ \\
E07 & 25 & 0 & $2,68^{\mathrm{c}} \pm 0,04$ & $0,37^{\mathrm{b}} \pm 0,01$ & $1,14^{\mathrm{e}} \pm 0,01$ & $19,33^{\mathrm{d}} \pm 0,59$ & $1,65^{\mathrm{c}} \pm 0,03$ \\
E08 & 25 & 50 & $2,93^{\mathrm{b}} \pm 0,01$ & $0,34^{\mathrm{b}} \pm 0,01$ & $1,26^{\mathrm{c}} \pm 0,01$ & $19,99^{\mathrm{d}} \pm 0,44$ & $1,78^{\mathrm{b}} \pm 0,01$ \\
E09 & 25 & 25 & $3,03^{\mathrm{e}} \pm 0,02$ & $0,30^{\mathrm{d}} \pm 0,01$ & $1,34^{\mathrm{b}} \pm 0,01$ & $26,66^{\mathrm{b}} \pm 2,08$ & $1,96^{\mathrm{ab}} \pm 0,01$ \\
E10 & 25 & 25 & $3,02^{\mathrm{e}} \pm 0,01$ & $0,31^{\mathrm{d}} \pm 0,01$ & $1,31^{\mathrm{b}} \pm 0,01$ & $25,33^{\mathrm{b}} \pm 0,57$ & $1,93^{\mathrm{ab}} \pm 0,01$ \\
E11 & 25 & 25 & $3,05^{\mathrm{e}} \pm 0,04$ & $0,34^{\mathrm{c}} \pm 0,01$ & $1,34^{\mathrm{b}} \pm 0,03$ & $25,48^{\mathrm{b}} \pm 0,53$ & $1,94^{\mathrm{ab}} \pm 0,02$ \\
\hline
\end{tabular}

${ }^{1}$ Letras distintas em uma mesma coluna apresentaram diferenças significativas ao nível de $5 \%$ de significância $(\mathrm{p} \leq 0,05)$ 
A solução de glazeamento promoveu diferenças significativas no volume específicos dos pães tipo forma, o maior valor foi observado para o ensaio 5 , com $3,19 \mathrm{~mL} / \mathrm{g}$, com solução composta de $25 \mathrm{~mL}$ de água, o menor foi observado para o ensaio 2 , com 2,49 mL/g, com solução contendo $37,5 \mathrm{~mL}$ de óleo de soja e $12,5 \mathrm{~mL}$ de água. Não apresentaram diferenças significativas entre si os ensaios 9 a 11; 2 e 4; 3 e 8 . A densidade dos pães variou de $0,30 \mathrm{~g} / \mathrm{mL}$ (ensaio 9) a $0,43 \mathrm{~g} / \mathrm{mL}$ (ensaio 4), não houve diferenças significativas entre os ensaios $1,3,6,7,8 ; 9$ e 10. O Índice de expansão variou de 1,05 para o ensaio 4, onde a solução foi composta de $37,5 \mathrm{~mL}$ de óleo de soja e $37,5 \mathrm{~mL}$ de água, o maior valor foi de 1,38 para o ensaio 5. O maior valor produzido foi pelo ensaio 5 , com $30,33 \mathrm{~mL}$ e o menor foi observado para o ensaio 4, com apenas $13,00 \mathrm{~mL}$, não houve diferenças significativas entre os volumes produzidos pelos ensaios 9 a $11 ; 6$ a $8 ; 1$ e 3 . O único ensaio que obteve fator de expansão máximo superior a $2,00 \mathrm{~cm}^{3}$ foi o que corresponde a solução de apenas $25 \mathrm{~mL}$ de água, o que demonstra que o óleo de soja foi prejudicial às características de expansão das massas.

A figura 2 apresenta a superfície de resposta e a curva de contorno da ação da solução de glazeamento sobre o fator de expansão máximo das massas.
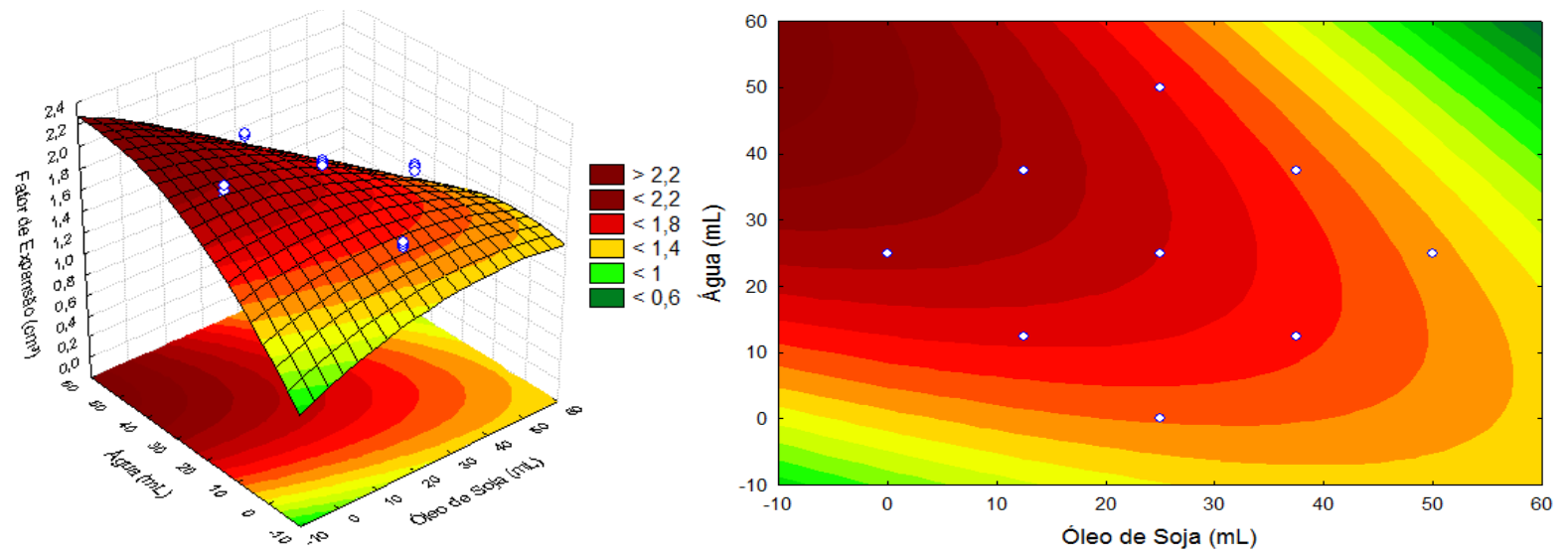

Figura 2 - Superfície de resposta, curva de contorno da ação da solução de glazeamento sobre sobre o fator de expansão máximo da massas

A região ótima de incorporação da solução de glazeamento composta por óleo de soja e água consistiu para valores maiores que $2,00 \mathrm{~cm}^{3}$, contendo de 30 a $35 \mathrm{~mL}$ de água e 0 a 10 $\mathrm{mL}$ de óleo. Observou-se que quando maior a quantidade de óleo adicionada, menor foi o fator de expansão obtido durante o processo fermentativo. Além disso, o óleo de soja pode ter agido como um fator limitante no processo de formação da crosta, limitando a expansão da massa, conforme explica Zhang et al. (2007)

A figura 3 apresenta a superfície de resposta e curva de contorno da ação da solução de glazeamento sobre o volume produzido das massas.

Resultado semelhante ao observado para o fator de expansão, a zona de otimização para o volume produzido foi correspondente à valores superiores a $20 \mathrm{~mL}$, com soluções contendo de 20 a $45 \mathrm{~mL}$ de água e de 0 a $5 \mathrm{~mL}$ de óleo de soja. Sem a adição de água, a solução de glazeamento produziu volumes inferiores a $20 \mathrm{~mL}$, prejudicando à qualidade física do produto. $\mathrm{O}$ resultado obtido neste presente estudo foi contrário ao que afirmam Lonegan et al. 
(1999), que a adição de solução de glazeamento sem a adição de água não afeta a qualidade do produto.
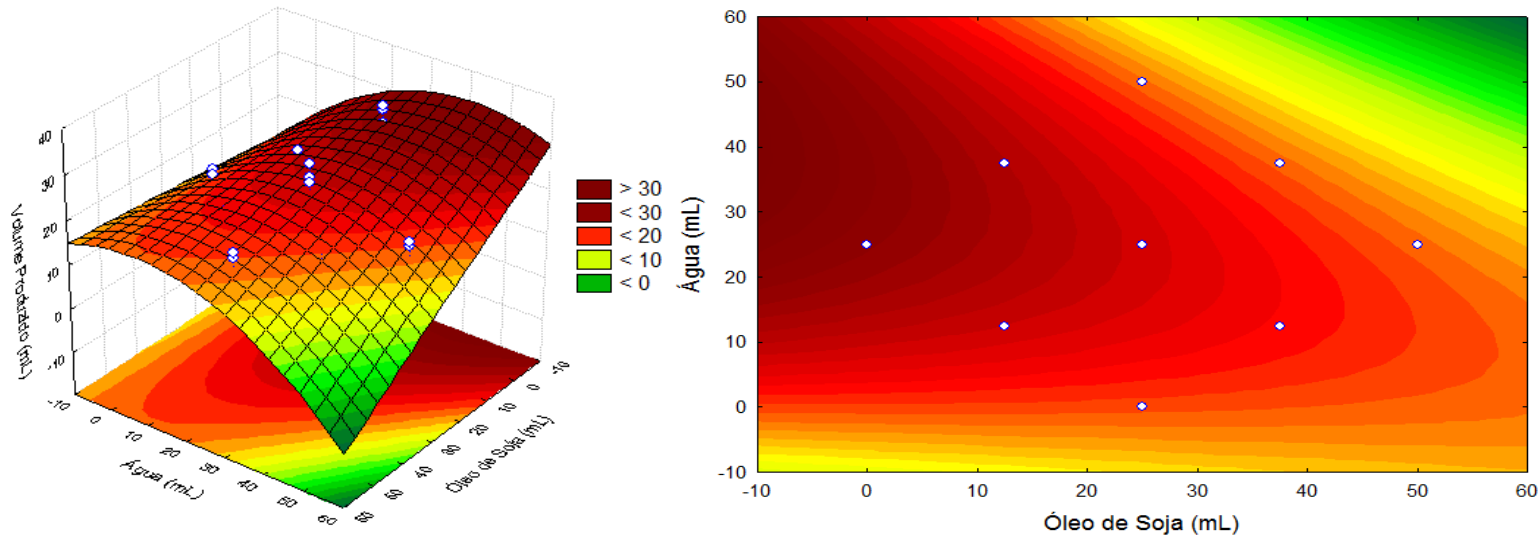

Figura 3 - Superfície de resposta e curva de contorno da ação da solução de glazeamento sobre o volume produzido das massas

A figura 4 fornece a superfície de resposta e curva de contorno da ação da solução de glazeamento no volume específico dos pães.
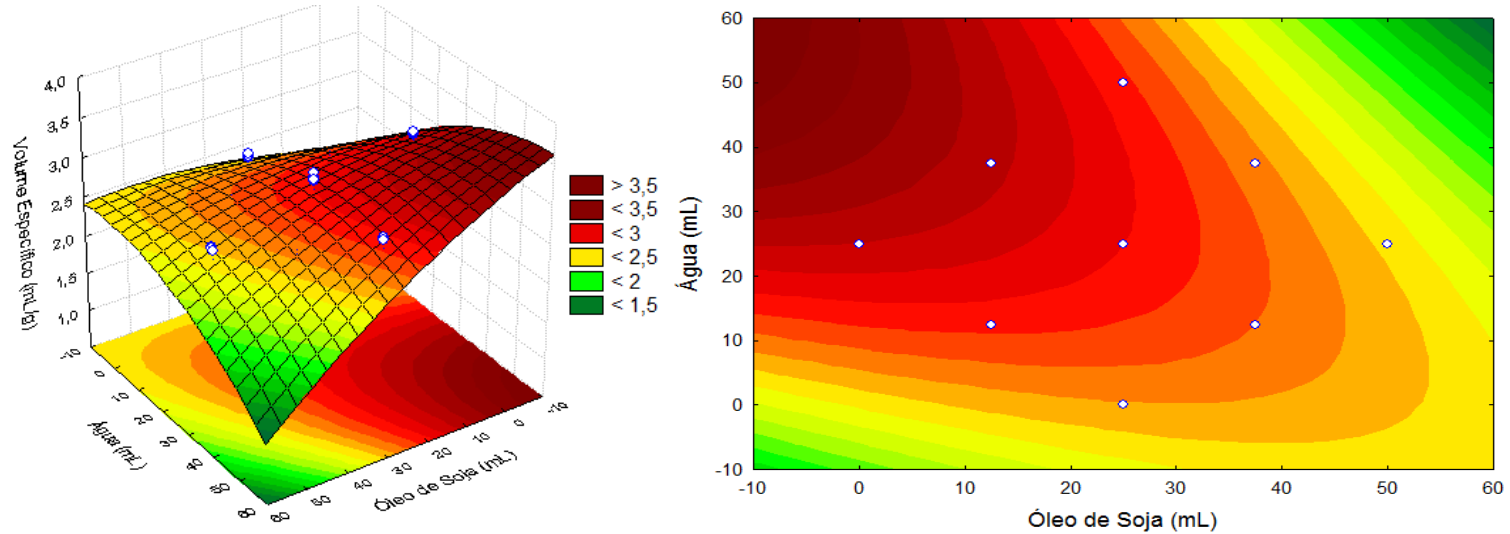

Figura 4 - Superfície de resposta, curva de contorno da ação da solução de glazeamento sobre o volume específico dos pães

Volumes específicos superiores a $3,00 \mathrm{~mL} / \mathrm{g}$ foram obtidos em soluções contendo a até $10 \mathrm{~mL}$ de óleo de soja e de $25 \mathrm{a} 45 \mathrm{~mL}$ de água. Se forem desenvolvidas soluções contendo apenas soluções de óleo de soja, o volume específico apresentado pelos pães será abaixo de $2,50 \mathrm{~mL} / \mathrm{g}$, o que comprova o efeito prejudicial deste tipo de óleo para o volume dos pães.

Jahromi et al. (2011) ressaltam que a perda de umidade da massa durante o processo de fermentação pode ocasionar a formação de estrutura rígida de barreira à umidade externa, causando fissuras e reduzindo o grau de expansão da massa, o óleo de soja, pode ter colaborado para a formação desta barreira e reduzindo à capacidade expansitiva da massa e consequente volume do pão.

A figura 5 apresenta a superfície de resposta e a curva de contorno da ação da solução de glazeamento sobre a densidade dos pães tipo forma. 

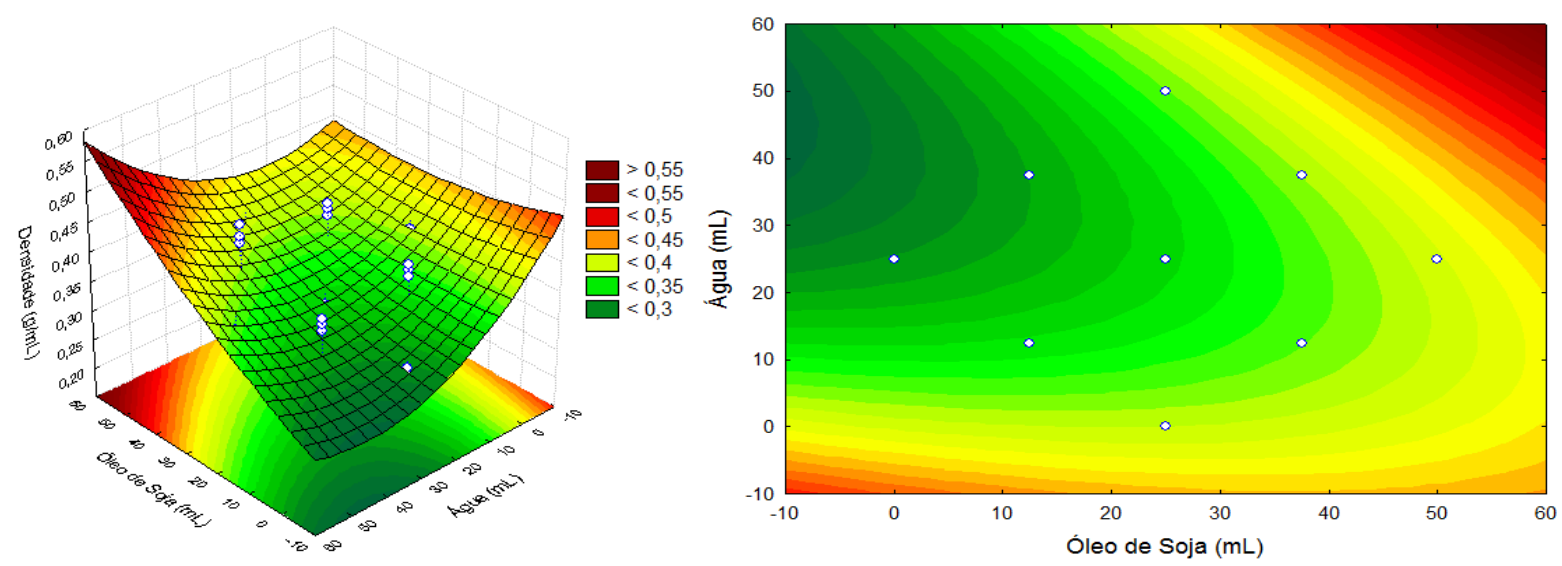

Figura 5 - Superfície de resposta e curva de contorno da ação da solução de glazeamento sobre a densidade dos pães

A densidade dos pães foi elevada conforme a quantidade de óleo de soja foi sendo incorporada na solução de glazeamento, a zona de otimização correspondeu à valores inferiores a $0,35 \mathrm{~g} / \mathrm{mL}$, para adição de até $5 \mathrm{~mL}$ de óleo de soja e de 25 a $45 \mathrm{~mL}$ de água, resultado semelhante ao encontrado para o volume específico. A figura 6 fornece a superfície de resposta e curva de contorno da ação da solução de glazeamento sobre o índice de expansão dos pães.
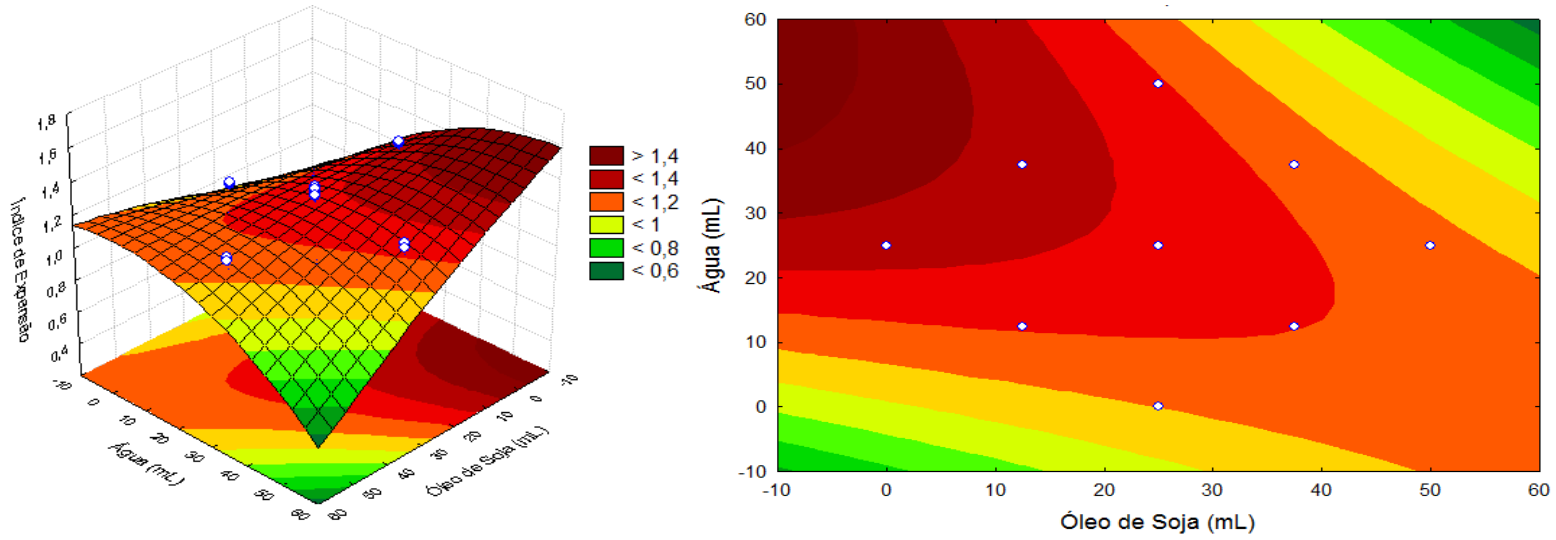

Figura 6 - Superfície de resposta e curva de contorno da ação da solução de glazeamento sobre o índice de expansão dos pães

Para o índice de expansão, a zona de otimização foi de valores acima de 1,20; que correspondente a incorporação de até $20 \mathrm{~mL}$ de óleo de soja e de 25 a $45 \mathrm{~mL}$ de água, verificou-se que a adição de quantidades inferiores a $20 \mathrm{~mL}$ de água e superiores a $25 \mathrm{~mL}$ de óleo de soja prejudicaram o índice de expansão dos pães.

\section{CONCLUSÃO}

O óleo de soja foi prejudicial às propriedades de expansão das massas e pães tipo forma em quantidades superiores a $15 \mathrm{~mL}$, para a água, a quantidade ótima foi estabelecida entre 25 e $40 \mathrm{~mL}$, de forma a produzir volumes específicos superiores a $3,00 \mathrm{~mL} / \mathrm{g}$ e fatores de expansão máximos acima de $2,00 \mathrm{~cm}^{3}$, melhorando às características físicas dos pães tipo forma. 


\section{REFERÊNCIAS}

AMERICAN ASSOCIATION OF CEREAL CHEMISTS - A. A. C. C. Approved methods of American Association of Cereal Chemists. 9 ed. St. Paul: 1995.

BÁRCENAS, M. E.; ROSELL, C. M. Different approaches for improving the quality and extending the shelf life of the partially baked bread: Low temperatures and HPMC addition. $J$. Food Eng., v. 72, p. 92-99, 2006.

CABELLERO, P. A.; GÓMEZ, M.; ROSELL, C. M. Improvement of dough rheology, bread quality and bread shelf-life by enzymes combination. J. Food Eng., v.81, p. 42-53, 2007.

FLANDER, L.; SALMENKALLIO-MARTILLA, M.; SUORTTI, T.; AUTIO, K. Optimization of ingredients and baking process for improved wholemeal oat bread quality. Food Sci. Technol., v. 40, p. 860-870, 2007

GABRIC, D.; BEN-AISSA, F.; LE-BAIL, A.; MONTEAU, J. Y.; CURIC, D. Impact of process conditions on the structure of pre-fermented frozen dough. J. Food Eng., v.105, p. 361-366, 2011.

JAHROMI, S. H. R.; YAZDI, F. T.; KARIMI, M.; MORTAZAVI, S. A.; DAVOODI, M. G. F.; POURFARZAD, A.; SOURKI, A. H. Application of glazing for bread quality improvement. Food Biop. Technol, v. 5, p. 2381-2391, 2012.

LONERGAN, D. A. Glaze for dough products. United States patent no 5965180, 1999.

RIBOTTA, P. D.; PÉREZ, G. T.; AÑON, M. C.; LEÓN, A. E. Optimization of additive combination for improved soy-wheat bread quality. Food Biop. Technol., v. 3, p. 395-405, 2008 .

SILVA, M. R.; GARCIA, G. K. S.; FERREIRA, H. F. Caracterização química, física e avaliação da aceitação de pão de queijo com baixo teor energético. Alim e Nutr, v. 14, n. 1, p. 69-75, 2003.

ZHANG, L. U.; LUCAS, T.; DOURSAT, C.; FLICK, D.; WAGNER, M. Effects of crust constraints on bread expansion and CO2 release. J. Food Eng., v. 80, p. 13021311, 2007. 